\title{
A origem da heterogeneidade da brotação em regiões de inverno ameno
}

\author{
Gabriel Berenhauser Leite'
}

\begin{abstract}
Resumo - Sob condições de inverno ameno, espécies frutíferas temperadas sofrem problemas agronômicos resultantes de brotamento e floração heterogêneos. O padrão de evolução da dormência e da brotação de pessegueiro foi estudado em plantas com: 1) Condições naturais de inverno em clima temperado (CN); 2) Privação parcial de frio (PPF); e 3) Privação total de frio (PTF). A endodormência das gemas vegetativas foi caracterizada por meio do teste de estacas de gema única. As plantas com privação de frio, tanto parcial como total, apresentaram evolução da dormência e taxa de brotação alteradas em relação às plantas sob CN. Os padrões de brotação dependeram dos padrões de saída da endodormência das gemas, tanto no tempo quanto no espaço. Em condições de inverno temperado, o gradiente de brotação tem origem na capacidade de crescimento das gemas após a saída da endodormência, enquanto em condições de privação parcial de frio a origem está na evolução diferencial da endodormência das gemas ao longo do ramo.
\end{abstract}

Termos para indexação: Prunus persica; dormência; privação de frio; evolução da dormência.

\section{The origin of the heterogeneity of budding in mild winter regions}

\begin{abstract}
Under mild winter conditions, temperate fruit trees suffer agronomic problems resulting from budding and flowering heterogeneous. The pattern of evolution of dormancy and budding from peach 'Redhaven' was studied with natural inter conditions (CN), partial deprivation of cold (PTF), and total deprivation of cold (PTF). Endodormence of the vegetative buds was characterized by the "one-node cuttings" test. The plants with cold deprivation (PPF and PTF) presented altered evolution of dormancy and budding rate in relation to $\mathrm{CN}$ plants. The budding patterns depended on the endodormence exit patterns of the buds, both in time and space. By the behavior observed in the evolution of dormancy and budding, we can infer that in temperate winter conditions, the budding gradient comes from the growth capacity of buds after leaving the endodormancy, while partial deprivation of cold is the origin of differential evolution of the endodormity of the buds along the branch.
\end{abstract}

Index terms: Prunus persica; dormancy; budding; cold deprivation; budburst.

\section{Introdução}

As plantas para sobreviverem a baixas temperaturas hibernais desenvolveram um mecanismo de adaptação que passa pela aquisição da resistência ao frio e de controle do crescimento, conhecida como dormência.

Em condições normais de clima temperado, após o frio recebido durante o inverno e o retorno das temperaturas favoráveis ao crescimento na primavera, as plantas retomam seu ciclo vegetativo e reprodutivo normalmente. Quando estas plantas são cultivadas em regiões com inverno ameno, onde a quantidade de frio não chega a satisfazer as necessidades básicas, observa-se a ocorrência de brotação e florescimento errático, caracterizado por uma baixa taxa de brotação e florescimento, tanto no tempo como espacialmente, ao longo do ramo. Além destes sintomas clássicos, Petri \& Leite (2004) descrevem diversas anomalias relacionadas com a falta de frio hibernal. Estas anomalias ocorrem durante o ciclo vegetativo nas gemas que conseguiram brotar, destacandose a paralisia no desenvolvimento do ramo, nas folhas e nos frutos pequenos e achatados, além de baixa frutificação efetiva. O uso de produtos químicos para a indução da brotação minimiza até certo ponto algumas destas anomalias, mas a sua eficiência está relacionada à época de aplicação, devendo as gemas já estar em processo de crescimento, ou seja, com a endodormência concluída.

\section{Modelos climáticos}

A época de aplicação é normalmente obtida através do uso de modelos climáticos, calculando-se a acumulação de frio e relacionando-a à necessidade em frio de cada cultivar. O problema é que a efetividade destes diversos modelos climáticos é reduzida quando os mesmos são utilizados fora da região onde foram desenvolvidos. Isto pode ser visto na Figura 1 , onde, mesmo sob condições de clima temperado, as respostas de dois modelos climáticos - o de Weinberger, que calcula as horas de frio $<7,2^{\circ} \mathrm{C}$ (WEINBERGER, 1954), e o de Utah, que calcula unidades de frio em relação a uma escala de temperaturas (RICHARDSON et al., 1974) - são totalmente contraditórias e, além disso, não repetitivas de ano para ano (LEITE, 2004). Apesar desta variação anual de previsão do fim da dormência nos dois modelos, os testes realizados com modelo biológico mostraram uma repetitividade na data de saída da endodormência.

Se tal nível de variação já ocorre em

${ }^{1}$ Eng.-agr., Dr., Epagri/Ciram, Rod. Admar Gonzaga, 1.347, Itacorubi - Caixa Postal 502 - CEP 88034-901 Florianópolis, SC, Brasil, e-mail: gabriel@epagri.sc.gov. 
condições de clima temperado, onde a variação de temperatura e a amplitude térmica no inverno podem ser consideradas baixas, o que ocorreria em condições subtropicais onde mesmo a quantidade de frio necessária para a saída da endodormência não é satisfeita?

\section{Evolução da dormência}

A evolução da dormência do pessegueiro Redhaven foi utilizada como modelo. Foram avaliadas três condições de temperaturas durante o inverno europeu: 1) Condição normal (CN) de inverno temperado (necessidade em frio das plantas completamente satisfeitas); 2) Privação parcial de frio (PPF) (necessidade em frio parcialmente satisfeita) e; 3) Privação total de frio (PTF) (sem acumulação de frio) (LEITE et al., 2004).

No tratamento $\mathrm{CN}$, as amostras foram coletadas de plantas em pomar. No tratamento PPF as amostras foram coletadas de plantas em contêineres de 200L, que foram transferidas para estufa em temperatura $>$ que $15^{\circ} \mathrm{C}$ após terem acumulado aproximadamente $60 \%$ de suas necessidades em frio (início de dezembro). No tratamento PTF as plantas foram transferidas para a mesma estufa antes do início do acumulo de frio (início de outubro). A evolução da endodormência foi avaliada pelo tempo médio de brotação (TMB), determinado pelo teste "estaca de gema única" (LEI$T E, 2004)$. As gemas foram separadas de acordo com sua posição no ramo (terminal, mediana e basal) para avaliação do gradiente ao longo do ramo. As análises foram realizadas desde o início de outubro até o início da brotação. A brotação foi analisada em planta através do acompanhamento dos estádios fenológicos.

A evolução da dormência e da brotação em condições naturais de inverno temperado (CN) é mostrada na Figura 2. No início de outono as gemas já estavam dormentes, chegando a uma intensidade máxima no final de outubro, reduzindo gradativamente até o final de fevereiro. Um forte gradiente basitônico de intensidade de dormência foi observado no início do outono, onde as gemas terminais apresentaram intensi-
(A)

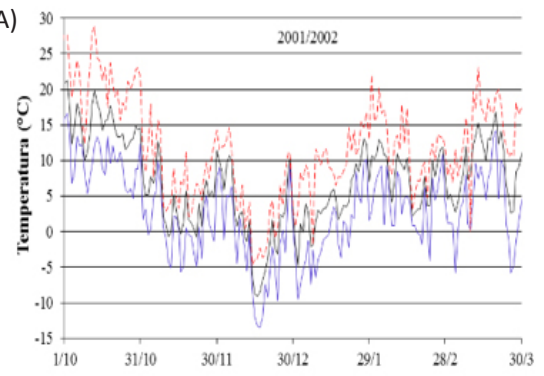

(B)
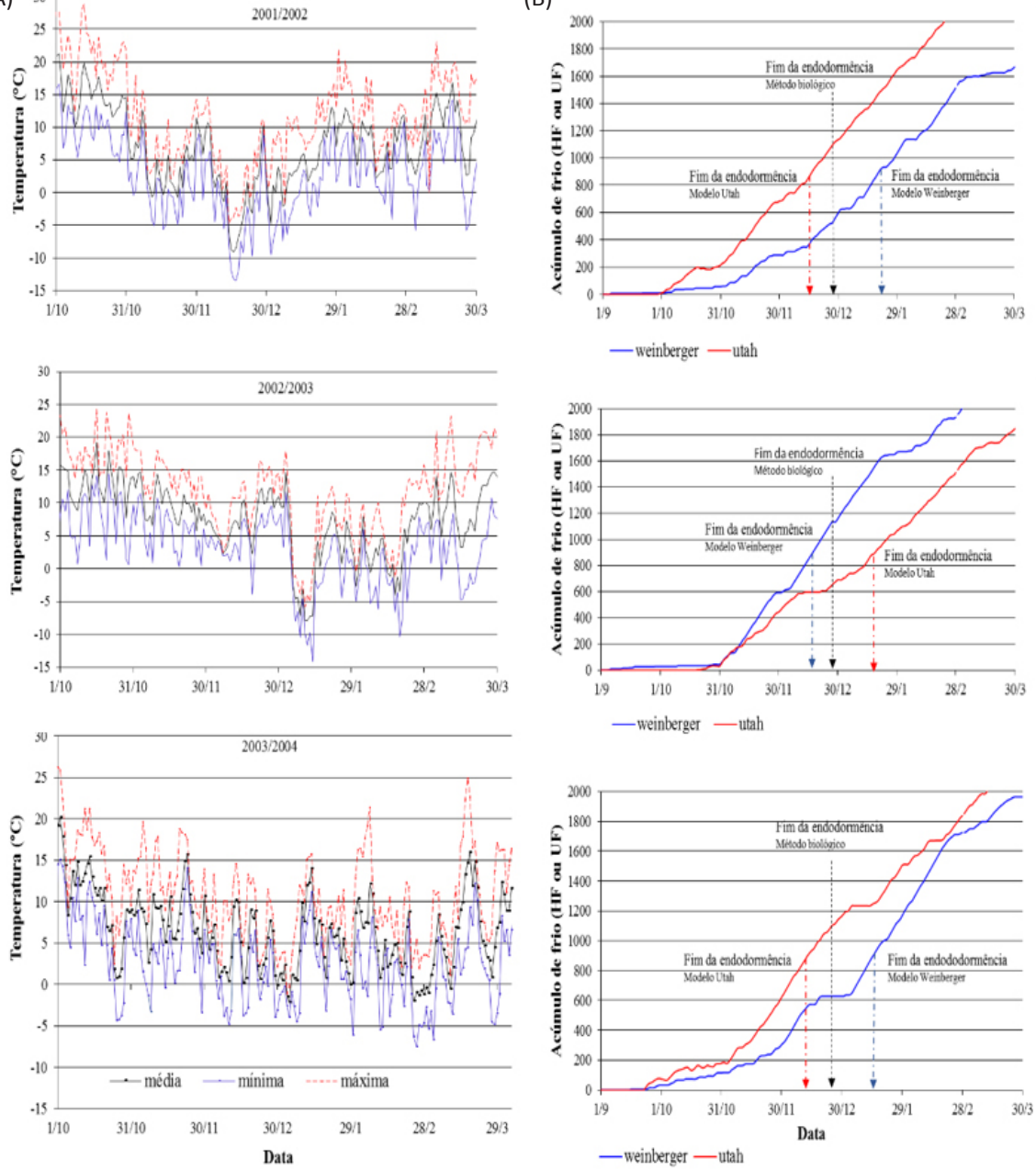

Figura 1. Dinâmica da temperatura máxima, média e mínima, durante o inverno, em 2000/2001, 2001/2002 e 2002/2003 (a) e a correspondente evolução da acumulação de horas de frio pelo método de Weinberger e unidades de frio pelo método Utah. ClermontFerrand (Lat $\left.48^{\circ} \mathrm{N}\right)$, França

Figure 1. Maximum, mean and minimum temperature dynamics during the winter, in 2000/2001,2001/2002 and 2002/2003 (a) and the corresponding evolution of the accumulation of cold hours by the Weinberger method and cold units by the Utah method. Clermont-Ferrand, France

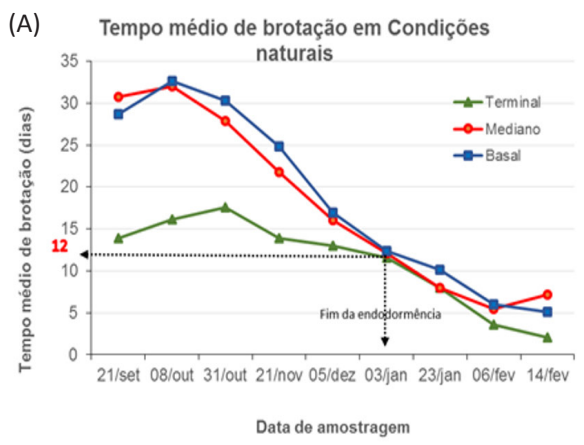

(B) Evolução da brotação em condiçöes naturais (\%)

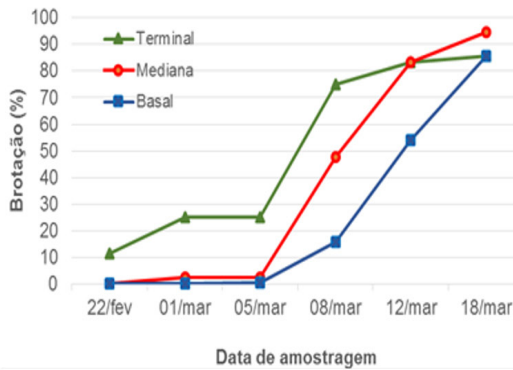

Figura 2. Evolução da dormência (tempo médio de brotação) (a) e da brotação (b) nas gemas terminais, axilares medianas e axilares basais, em condições normais de inverno temperado. Clermont-Ferrand, França

Figure 2. Evolution of dormancy (mean sprouting time) (a) and sprouting (b) in terminal, medial axillary and basal axillary buds under normal temperate winter conditions.

Clermont-Ferrand, France 
dade inferior às gemas axilares. Neste ponto o pessegueiro diferencia-se de outras espécies temperadas como a macieira e a pereira, que apresentam as gemas terminais mais dormentes do que as axilares nesta época (gradiente acrotônico). Esse gradiente inicial vai diminuindo gradativamente, com as três curvas chegando ao mesmo tempo no ponto em que se considera a saída da endodormência, que no caso específico da cv. Redhaven é de 12 dias (TMB). Após este ponto, observa-se a formação de um outro gradiente que pode ser interpretado como a capacidade de crescimento da gema. As gemas terminais apresentam uma redução mais rápida em relação às axilares, formando ao final um gradiente acrotônico de capacidade de crescimento. Esta capacidade de crescimento acrotônico observada no teste de estacas de gema única, após a saída da endodormência, coincide com o gradiente de brotação observado nas plantas, onde houve uma antecipação da brotação dos terminais seguida primeiro pelas gemas axilares medianas e depois pelas basais (Figura 2).

Quando a planta é privada totalmente do frio (PTF) (Figura 3), observou-se uma redução inicial da intensidade de dormência, como em condições naturais, mas em janeiro (correspondente a julho no Brasil) os valores se estabilizaram ao redor do TMB 20 dias, indicando uma persistência da endodormência. Isto se confirma com a ausência de brotação observada nestas plantas. Este resultado demonstra incontestavelmente a necessidade da ação de frio no processo de saída da dormência das plantas caducifólias.

Em condições de uma privação parcial de frio (PPF), onde a planta recebeu uma certa quantidade de frio, mas não o suficiente para satisfazer seu requerimento, a evolução da dormência e a dinâmica da brotação na planta foram alteradas substancialmente (Figura 4). A taxa de brotação foi baixa e o período prolongou-se por mais de 30 dias. No início, as gemas terminais se anteciparam em relação às axilares, mas em seguida foram alcançadas pelas gemas basais e ultrapassadas no final, formando um gradiente basitônico de brotação.

\section{Tempo médio de brotação em privação total} de frio

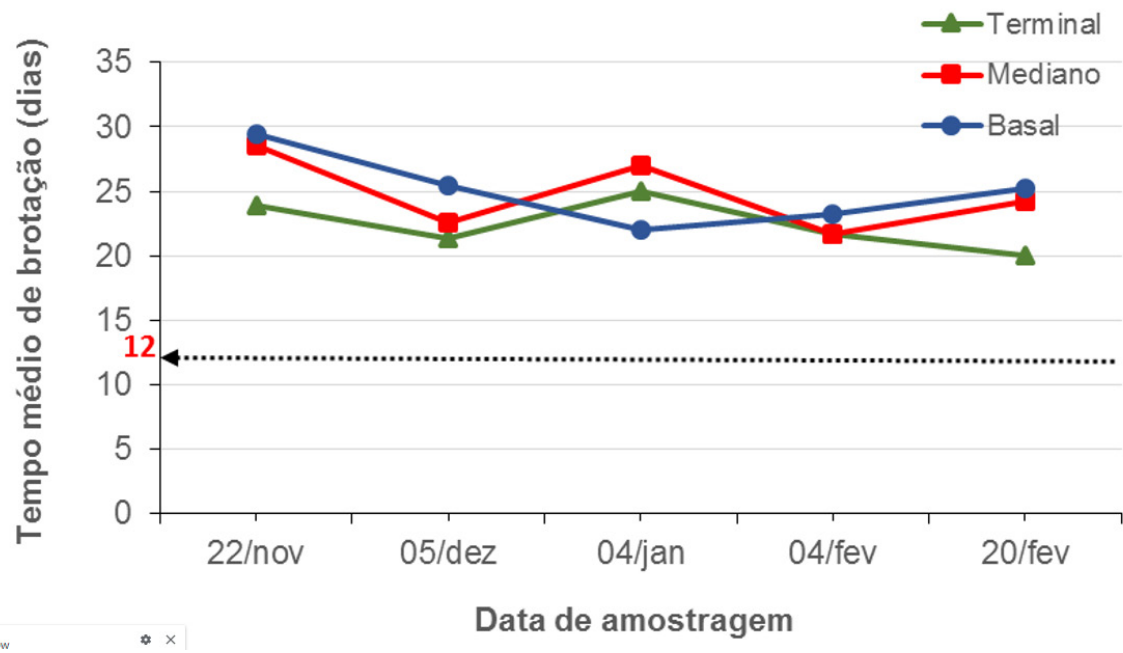

Figura 3. Evolução da dormência (tempo médio de brotação), nas gemas terminais, axilares medianas e axilares basais, em condições de privação total de frio no inverno. ClermontFerrand, França

Figure 3. Evolution of dormancy (mean budding time), in terminal buds, medial axillary buds and basel axillary buds, under total cold deprivation in winter. Clermont-Ferrand, France
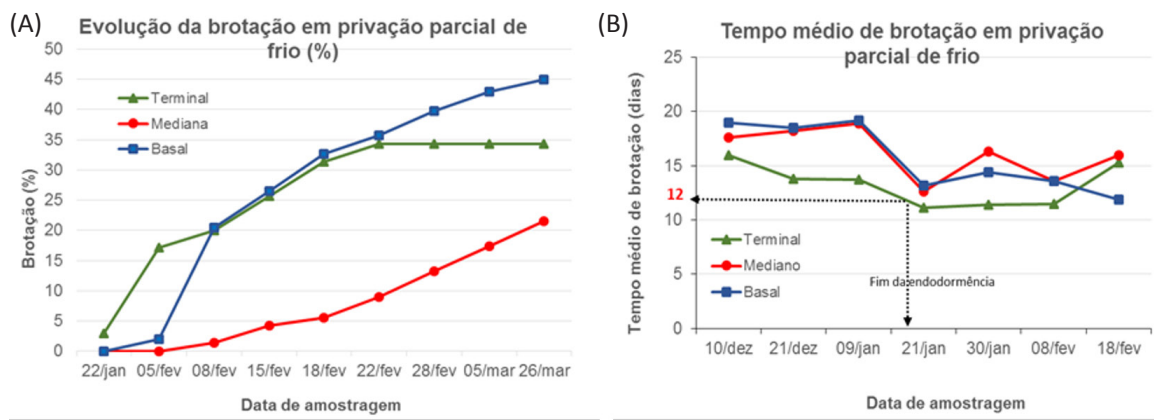

Data de amostragem

Figura 4. Evolução da dormência (tempo médio de brotação) (a) e da brotação (b) nas gemas terminais, axilares medianas e axilares basais, em condições de privação parcial de frio no inverno. Clermont-Ferrand, France

Figure 4. Evolution of dormancy (mean budding time) (a) and sprouting (b) in terminal buds, medial axillary buds and basal axillary buds, under partial cold deprivation in winter. Clermont-Ferrand, France

As gemas medianas apresentaram uma taxa de brotação $50 \%$ inferior à dos terminais e basais.

A taxa de diminuição da intensidade de dormência em dezembro, após a transferência para a estufa, foi menor em relação ao observado em condições naturais. A diferença entre as gemas terminais e as axilares praticamente se mantiveram até meados de janeiro, quando em todos os níveis do ramo a intensidade se aproximou do nível de saída de endodormência (TMB $<12$ dias), mas com as gemas terminais chegando antes neste nível. Se ficássemos apenas na descrição da evolução pela média das gemas por nível, diríamos que as gemas terminais teriam saído da endodormência no dia 20 de janeiro, enquanto as gemas axilares continuariam endodormentes.

\section{Heterogeneidade da brotação}

Analisando-se os valores individuais do TMB (não somente a média) e a brotação na planta, observou-se que 
Tabela 1. Evolução da repartição das gemas segundo suas posições e seus estados ao longo do ramo em privação parcial de frio. ClermontFerrand, França

Table 1. Evolution of bud distribution according to their positions and their states along the branch in partial cold deprivation. ClermontFerrand, France

\begin{tabular}{lcccccccccc}
\hline Data & $\begin{array}{c}\text { \% de gemas endodormentes } \\
\text { (tempo individual de brotação } \\
\text { (12 dias) }\end{array}$ & $\begin{array}{c}\text { \% de gemas não endodormentes } \\
\text { e não brotadas }\end{array}$ & \multicolumn{2}{c}{ \% de gemas brotadas } \\
\hline & Terminal & Mediana & Basal & Terminal & Mediana & Basal & Terminal & Mediana & Basal \\
\hline $10 / 12$ & 100 & 100 & 100 & 0 & 0 & 0 & 0 & 0 & 0 \\
\hline $21 / 12$ & 100 & 100 & 100 & 0 & 0 & 0 & 0 & 0 & 0 \\
\hline $09 / 01$ & 56 & 94 & 86 & 44 & 6 & 14 & 0 & 0 & 0 \\
\hline $21 / 01$ & 25 & 53 & 53 & 75 & 47 & 47 & 0 & 0 & 0 \\
\hline $30 / 01$ & 40 & 79 & 76 & 50 & 21 & 23 & 10 & 0 & 1 \\
\hline $08 / 02$ & 40 & 75 & 44 & 40 & 23 & 36 & 20 & 2 & 20 \\
\hline $18 / 02$ & 60 & 75 & 33 & 10 & 20 & 36 & 30 & 5 & 31 \\
\hline
\end{tabular}

no dia $9 / 01,44 \%$ das gemas terminais já tinham saído da endodormência contra $6 \%$ das medianas e $14 \%$ das basais, com nenhuma gema brotada na planta (Tabela 1). Entre os dias 9 e 21/01, a percentagem de gemas que saíram da endodormência aumentou em todos os níveis, sendo $75 \%$ dos terminais e $45 \%$ das medianas e basais, sem ainda nenhuma brotação na planta. Entre os dias 21 e $30 / 01$, quando $10 \%$ das gemas terminais já tinham brotado, observou-se uma retração na evolução da dormência, ocorrendo um aumento da intensidade em todos os níveis. A explicação para este evento estaria no aparecimento da paradormência, sendo a paralisação do crescimento originada em outra estrutura da mesma planta. Neste caso, o crescimento antecipado das gemas terminais, que saíram da endodormência antes das outras gemas, inibe o crescimento das demais gemas pela ação das auxinas, num caso característico de dominância apical. A maior inibição observada nas gemas medianas poderia ser explicada pela maior proximidade da origem da paradormência, que é a gema terminal em relação às gemas basais.

A heterogeneidade e o gradiente de intensidade de dormência final, ob- servados no teste de estacas de gema única, se expressaram integralmente na heterogeneidade e no gradiente final de brotação na planta (Figura 4), demonstrando que o comportamento errático da brotação em condições de inverno ameno está diretamente relacionado à alteração da evolução da dormência ao longo do ramo.

\section{Considerações finais}

Pelo comportamento observado na evolução da dormência e da brotação, podemos inferir que, em condições de inverno temperado, o gradiente de brotação tem origem na capacidade de crescimento das gemas após a saída da endodormência, enquanto, em condições de privação parcial de frio, a origem está na evolução diferencial da endodormência de cada gema ao longo do ramo.

\section{Referências}

HERTER, F.G. Dormance de bourgeons et phenologie de quelques cultivar de pommier: effet de la température en interaction avec le génotype. 1992. 162p. Tése. (Doutorado em Fisiologia Vegetal) - Universidade Blaise Pascal, Clermont-Ferrand, França.
LEITE, G.B.; BONHOMME, M.; LACOINTE, A.; RAGEAU, R.; SAKR, S.; GUILLIOT, A.; MAUREL, K.; PETEL, G.; RODRIGUES, A. C. Influence of Lack of Chilling on Bud-break Patterns and Evolution of Sugar Contents in Buds and Stem Tissues along the One-year-old Shoot of the Peach Trees. Acta Horticulturae, Brugge, v. 662, p. 61-71, 2004.

\section{LEITE, G.B. Évolution des états de bourgeons} et leur hétérogénéité le long du rameau d'un an de pêcher sous differents régimes de temperatures aprés l'installation de l'endodormance. 2004. 168p. Tese. (Doutorado em Fisiologia Vegetal) - Universidade Blaise Pascal, Clermont-Ferrand, França.

PETRI, J.L.; LEITE, G.B. Consequences of Insufficient Winter Chilling on Apple Tree Budbreak. Acta Horticulturae, Vol. 662, pp. 5360, 2004.

RICHARDSON, E.A.; SEELEY, S.D.; WALKER, D.R. A model for estimating the completion of rest for Redhaven and Alberta peach trees. HortScience, v.9, n.4, p. 331-332. 1974.

WEINBERGER, J.H. Effects of high temperatures during the breaking of the rest of Sullivan Elberta peach buds. Proceedings of the American Society for Horticultural Science, v.63, p.157-162.1954. 